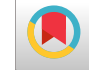

\title{
Provision of an Empirical Model to Estimate the Adaptive Capacity of Workers at Risk of Heat Stress
}

\author{
Mehdi Asghari, ${ }^{1}$ Parvin Nassiri, ${ }^{2,}{ }^{*}$ Mohammad Reza Monazzam, ${ }^{3}$ Farideh Golbabaei, ${ }^{2}$ Ali Aliakbar \\ Shamsipour, ${ }^{4}$ and Hossein Arabalibeik ${ }^{5}$ \\ ${ }^{1}$ Department of Occupational Health, School of Public Health, Arak University of Medical Sciences, Arak, Iran \\ ${ }^{2}$ Professor, Department of Occupational Health, School of Public Health, Tehran University of Medical Sciences, Tehran, IR Iran \\ ${ }^{3}$ Professor, Department of Occupational Health, School of Public Health and Center for Air Pollution Research (CAPR), Institute for Environmental Research (IER), Tehran \\ University of Medical Sciences, Tehran, IR Iran \\ ${ }^{4}$ Associate Professor, Department of Physical Geography, School of Geography, University of Tehran, Tehran, IR Iran \\ ${ }^{5}$ Research Center for Science and Technology in Medicine (RCSTIM), Tehran University of Medical Sciences, Tehran, IR Iran \\ "Corresponding author: Parvin Nassiri, Professor, Department of Occupational Health, School of Public Health, Tehran University of Medical Sciences, Tehran, IR Iran. Tel: \\ +98-2188951390, Fax: +98-2188954781, E-mail: nassiri@sina.tums.ac.ir
}

Received 2016 August 16; Revised 2016 November 19; Accepted 2017 January 13.

\begin{abstract}
Background: Workers exposed to extreme heat in the workplace may be at risk of various heat related-illnesses. There are different ways to control heat stress in the workplace. Adaptation to heat is a process by which the body can cope with the heat stress and remove the excess heat. Some criteria affect the adaptability parameter. The present study aimed at determining some important criteria for adaptability to heat.

Methods: The most important criteria were extracted according to experts' opinions and by Delphi model, their weights were specified by fuzzy analytic hierarchy Process (FAHP), and a model was introduced for adaptability. The weights of criteria determined by FAHP were used for prioritization.

Results: The maximum percentage of responses (100\%) with the relative weight of 0.063 was allocated to the criterion of administrative control. Engineering controls (86.6\%), providing shaded area and special places for rest (70\%), and having access to healthy drinking water (60\%) were considered as other effective criteria for adaptability. Having a second job, personal protective plans, training programs and suitable working clothes can also affect adaptation to heat.

Conclusions: In conclusion, adaptability will enable the workers to work in hotter environments for longer periods. According to obtained percentages and weights, the introduced model can be used to prioritize the suitable measures for improving the adaptability of workers and controlling the heat stress. Developing a heat stress control program and implementing this policy requires the cooperation of all members, especially employees.
\end{abstract}

Keywords: Heat Stress, Adaptive Capacity, Heat Stress Disorders/Mortality, Fuzzy AHP, Workers

\section{Background}

Exposure to the extreme heat or working in hot workplaces increases the risk of heat stress and can cause occupational illnesses and injuries. Workers exposed to hot indoor or outdoor environments are at risk of heat-related illnesses. Some symptoms such as heat rash, heat cramps, heat exhaustion, heat stroke, loss of consciousness, and chronic kidney diseases may result from exposure to extreme heat $(1,2)$. Heat is also known as a risk factor for cardiovascular diseases (3). High physical activity in hot environments may cause an increase in the core body temperature (above $38^{\circ} \mathrm{C}$ ), reduce physical work capacity, and decrease mental task ability. In addition, increasing the risk of accident and heat-related illnesses is also possible $(4,5)$.
During the last century, the global average temperature has increased $0.74^{\circ} \mathrm{C}$. Further increase in global average temperature, about $1.8-4.0^{\circ} \mathrm{C}$, would be expected around 2100 (6). Outdoor workers including farmers, construction workers, miners in surface mines, fishers, foresters, people who work in industries related to tourism, health, and business as well as workers of small and medium workshops with no ventilation system are at great risk of heat stress and climatic changes (7).

Some irreparable effects, even death, may result from exposure to heat stress. Many workers are exposed to the extreme heat around the world. In the United States, approximately 5 to 10 million workers may be at risk of heat stress (8). According to statistics, 423 workers died due to exposure to heat stress in the United States between 1992 
and 2006 (9). In Japan, 13.8 deaths per year were recorded between 1991 and 2001 (10). Based on the estimation of U.S centers for disease control and prevention, an average of 175 deaths between 1979 and 2003 occurred due to heat, which includes mortalities from hurricanes, lightning, tornadoes, and floods (11).

It seems that the mortality rates caused by working in hot workplaces can impose large costs on the industries. Estimations indicate that the average cost per a heatrelated illness may be about \$ 7500 (12). In recent years, the safety and health administrations of the federal government and state of California have placed heat-related illnesses at the top of their priorities (13).

Some ways have been recommended to reduce the mortality rate and minimize the health effects due to the heat stress, which are as follow: avoiding exposure to heat as much as possible; suitable training for workers; and good behavior during exposure to heat, for instance, increasing daily water consumption and seeking medical attention. These preventive ways, as well as considering some measures for adaptation of workers to the heat, can effectively reduce heat stress. Planning control measures for outdoor workers exposed to heat is more difficult than indoor ones. Therefore, heat-related illnesses are more common in these workers. Due to the lack of efficient protection methods, workers are exposed to extreme heat and high humidity in workplaces, and thus they are susceptible to the adverse effects of heat stress and climate changes (14).

The ability of system to cope with climate changes and adapt to extreme heat to reduce the risks and consequences resulted from these conditions is called adaptive capacity. Adaptation leads to reducing the vulnerability and increasing heat tolerance (15). Adaptive capacity is defined as "The ability of a system to adjust to climate change, to moderate potential damages, to take advantage of opportunities, or to cope with the consequences" (16). The ability of workers to work in thermal conditions reflects adaptation through complex behaviors and the development of workplace, clothing, and technology. Body size, individual life history, and nutritional status are the other effective factors for adaptation. Workers productivity may reduce without adaptation to the work conditions. Physiologically, humans adapt to heat by increasing the efficacy of physiological heat loss mechanisms and increasing their cardiovascular capacity. Reducing the heat strain and improving the physical performance are results of adaptation. A relationship between physiological and psychological aspects of work in the heat affects the maximal adaptability. Therefore, considering different criteria affecting adaptability to heat is highly important for estimating adaptive capacity $(16,17)$.
Due to the fact that there are no guidelines and instructions to determine the criteria for adaptability in the workplace, the present study aimed at calculating this important parameter in work environments. At first, some criteria were considered by Delphi model and then the weights of effective criteria were determined using the fuzzy analytic hierarchy process (FAHP). Eventually, a structural equation was proposed for the adaptability parameter.

\section{Methods}

This qualitative and practical study was designed and performed in 10 steps. Since there were no common criteria for adaptability parameter, the Delphi technique was applied. The first paper on Delphi technique was published more than 50 years ago. The development of this technique by Dalkey and Helmer at the Rand Corporation goes back to the 1950s. Delphi, as an effective and highly flexible technique, is used to achieve consensus or forecast future events. It is a proper method to collect the opinions of experts, who cannot easily meet each other due to geographical distance. Using Delphi as a research method is useful when there is no integrated knowledge about a specific issue or problem. This technique has been defined as a mean for consensus-building using a series of questionnaires to achieve the viewpoints of experts about the selected topic. In this method, the data obtained in each step are used in the next one, and this process will continue to achieve the consensus of experts. For this purpose, the questionnaires were sent to obtain the experts' opinions in at least 2 or 3 rounds. In fact, the consensus in Delphi means the participants agreement on the viewpoints to establish a new common view (18).

Briefly, the characteristics of Delphi technique are as follow:

- The panel of experts

- Repeated responding to questionnaires and controlled feedback of the results obtained from previous rounds

- The statistical analysis of the responses

- The anonymity of participants

The ability to collect and use the opinions of experts from wide geographical distances, the freedom of individuals to express their opinions, the experts' participation in their preferred time, and cost-effectiveness are some advantages of Delphi technique (19).

Given the mentioned advantages of Delphi method as well as the lack of common criteria for the adaptability parameter in the workplaces, the present study aimed at determining the effective criteria for adaptability using the experts' viewpoints and then weighing these criteria. 
In Delphi technique, like other practical researches, planning and effective implementation of the study should be considered. This technique includes 4 key activities:

1. Defining the problem

2. Selecting the group

3. Determining the group size

4. Implementing the Delphi rounds

The implementation of this study includes 10 steps, which are as follow:

1. Establishing an executive team and monitoring the implementation of Delphi

2. Selecting the experts

3. Adjusting the questionnaire for the first round

4. Editing the questionnaire grammatically (remove any ambiguity)

5. Sending the first questionnaire to the experts

6. Analyzing the results of obtained responses in the first round

7. Preparing the questionnaire with required revisions for the second round

8. Sending the second questionnaire to experts

9. Analyzing the responses obtained in the second round

10. Determining the relative weights of criteria using the fuzzy analytic hierarchy process (FAHP)

In the first step, an implementing and monitoring team was formed and the aims of the study were reviewed again. The experts participating in the study as the Delphi panel members included professors of occupational health departments in universities of medical sciences and executive experts of the environmental health department of the ministry of health. In total, 30 individuals participated in this study. According to the literature, if the background of the participants in Delphi process is homogeneous, a sample consisting of 10 to 15 individuals will be enough to obtain significant results. Because absence of some respondents during the study was likely, 30 individuals were selected to ensure the validity of obtained results.

At first, an open question with understandable concept was designed as a pilot survey and sent to 10 experts to obtain their responses and perceptions. Given the results of the pilot study, the questionnaire was sent to the 30 mentioned individuals. Then, following the analysis of responses of the first round, the common criteria were extracted and scored. Also, other criteria with lower scores were surveyed. During several meetings with the experts, some criteria were merged due to having the same concepts and overlapping, moreover, non-measurable and unrelated criteria were deleted. At the end of the meetings, criteria with the maximum scores were extracted and used to prioritize and perform pair-wise comparisons in the next round. Then, a checklist was sent to 30 experts to obtain pair-wise comparisons between criteria and determine their weights using the FAHP.

\subsection{Fuzzy Analytic Hierarchy Process}

The analytic hierarchy process, one of the most comprehensive systems, is defined as a technique for making decisions according to different criteria. It can hierarchically formulate the problem considering the qualitative and quantitative criteria. Since the AHP is compatible to human thinking processes and its structure is based on mathematical algorithm, it can be used as an efficient technique to solve many problems with decision- making. In addition, there is no need for complex mathematics when using AHP, as it is an easily perceptual technique and can control both qualitative and quantitative data. The analytic hierarchy process uses the multi-criteria framework for decision-making and assesses the problem based on experts' viewpoints. The allocation of single crisp value to experts' viewpoints is a potential drawback of AHP. Therefore, fuzzy AHP, as an alternative approach for traditional AHP, applies a range of values to overcome the uncertainty of experts' opinions. These values as fuzzy triangular numbers are used to determine the weights of criteria (20).

The Fuzzy AHP is described in the following steps:

Developing a Fuzzy Comparison Matrix and Determining Linguistic Variables

At first, 9 basic linguistic terms were considered with respect to a fuzzy 9 level scale. These terms were as follow: "Equal", "Weak advantage," “Not Bad," "Preferable," "Good," "Fairly good," "Very good," "Absolute" and "Perfect". The membership function defined by Gumus was applied as triangular fuzzy numbers (TFN) from 1 to 9 (Table 1) (21). A triple of real numbers ( $1, \mathrm{~m}$, and $\mathrm{u}$ ) are applied for characterizing a TFN, wher, parameters of $\mathrm{m}, \mathrm{l}$, and $\mathrm{u}$ show the maximal grade of the membership function $\mu(\mathrm{x})$, the lower, and the upper bounds, respectively. They limit the field of the possible evaluation.

$\mu(x)=\left\{\begin{array}{c}\frac{(x-l)}{m-l}, \ldots x \in[l, \mathrm{~m}] \\ \frac{(u-x)}{(u-m)}, \ldots \mathrm{x} \in[m, \mathrm{u}] \\ 0, \ldots \text { Otherwise }\end{array}\right.$

Then, the pair-wise comparison matrix for the main criteria and subcriteria was performed using the TFN. This fuzzy comparison matrix can be seen in Figure 1.

Definition of the Fuzzy Geometric Mean:

Equation (3) was used to compute the fuzzy geometric mean (20).

$\tilde{r}_{i}=\frac{\left(\tilde{a}_{i 1} \otimes \tilde{a}_{i 1} \otimes \ldots \otimes \tilde{a}_{i n}\right) 1}{n}$ 
Table 1. Membership Function of Linguistic Scale

\begin{tabular}{lcc}
\hline Linguistic & Fuzzy Number & Scale of Fuzzy Number \\
\hline Equal & 1 & $(1,1,1)$ \\
\hline Weak advantage & 2 & $(1,2,3)$ \\
\hline Not bad & 3 & $(2,3,4)$ \\
\hline Preferable & 4 & $(3,4,5)$ \\
\hline Good & 5 & $(4,5,6)$ \\
\hline Fairly good & 6 & $(5,6,7)$ \\
\hline Very good & 7 & $(6,7,8)$ \\
\hline Absolute & 8 & $(7,8,9)$ \\
\hline Perfect & 9 & $(8,9,10)$ \\
\hline
\end{tabular}

$$
\tilde{\boldsymbol{A}}=\left[\begin{array}{cccc}
1 & \tilde{a}_{12} & \cdots & \tilde{a}_{1 n} \\
\tilde{a}_{21} & 1 & \cdots & \tilde{a}_{2 n} \\
\vdots & \vdots & \ddots & \vdots \\
\tilde{a}_{n 1} & \tilde{a}_{n 2} & \cdots & 1
\end{array}\right]=\left[\begin{array}{cccc}
1 & \tilde{a}_{12} & \cdots & \tilde{a}_{1 n} \\
1 / \tilde{a}_{12} & 1 & \cdots & \tilde{a}_{2 n} \\
\vdots & \vdots & \ddots & \vdots \\
1 / \tilde{a}_{1 n} & 1 / \tilde{a}_{2 n} & \cdots & 1
\end{array}\right]
$$

Figure 1. This Fuzzy Comparison Matrix

In this equation, $\tilde{a}$ in gives a value of fuzzy comparison matrix from criteria i to $n$. Results obtained from the fuzzy geometric mean will later be called the local fuzzy number.

Calculation of the Fuzzy Weight of Each Dimension:

In this step, Equation 4 was used to calculate the global fuzzy number for each evaluation dimension.

$$
\tilde{W}_{i}=\tilde{r}_{1} \otimes\left(\tilde{r}_{1} \oplus \tilde{r}_{1} \oplus \ldots \oplus \tilde{r}_{1}\right)^{-1}
$$

Definition of the Best Nonfuzzy Performance (BNP):

To find the value of BNP from the fuzzy weight of each dimension, the fuzzy number was converted to crisp weight value using the centre of area ( $\mathrm{COA})$ method and Equation 5 (22).

$B N P i=\frac{\left[\left(u_{i}-l_{i}+\left(m_{i}-l_{i}\right)\right)\right]}{3}$

\subsection{Calculation of Consistency Ratio of the Matrix}

The consistency of pair-wise comparison matrices is considered for decision-making in AHP. The consistency of judgments is described by consistency ratio (CR). It is calculated by Equation 6, where CI and RI are the consistency index and the consistency of a random matrix, respectively. These parameters are extracted from related tables.

$C R=\frac{C I}{R I}$
The pair-wise comparisons and judgments are acceptable, when the CR is less than 0.1. The CR higher than 0.1 indicates inconsistent judgment (23).

The weighing of the criteria was only used in the present study. Experts used Table 1 to conduct the pairwise comparisons. To extract the related data, the completed questionnaires and pair-wise comparisons matrices as well as the determined priority by each person were used. Then, preliminary data process was done by Excel software. Eventually, the arithmetic average of obtained responds and the coefficient of each pair comparison were determined using the MATLAB software for the 30 experts who participated in the study.

\section{Results}

The present study aimed at determining the effective criteria and their weights for adaptability to heat using Delphi and fuzzy analytic hierarchy process (FAHP). Tables 2 and 3 demonstrate the criteria obtained from the Delphi model and the final criteria, respectively. As observed in Table 3, the maximum percentage of agreements (100\%) was allocated to administrative controls. Other criteria such as providing shade and special places for rest, having access to healthy drinking water, providing necessary electrolytes for the body, and local cooling systems were merged as engineering controls. Criteria of suitable diet, subsistence condition, and existing facilities for taking a shower after work were excluded due to very low percentage of the responses. The inconsistency rate of 0.065 in this study was lower than 0.1, indicating an acceptable and proper level. According to the purpose of this study, the weights of 13 selected criteria were determined by the analytic hierarchy process. The results of the paired comparisons have are presented in Table 2.

The Adaptive Capacity computed based on mentioned criteria is expressed by the following Equation 7:

$$
\begin{aligned}
\text { Adaptive Capacity }= & 0.099 \mathrm{~A}+0.156 \mathrm{~B}+0.073 \mathrm{C}+0.109 \mathrm{D} \\
& +0.116 \mathrm{E}+0.090 \mathrm{~F}+0.028 \mathrm{G} \\
& +0.081 \mathrm{H}+0.08 \mathrm{I}+0.056 \mathrm{~J} \\
& +0.035 \mathrm{~K}+0.024 \mathrm{~L}+0.053 \mathrm{M}
\end{aligned}
$$

Administrative controls (A): Yes (1), No (0)

Engineering controls (B): Yes (1), No (0)

Providing special places for rest and shaded area (C): Yes (1), No (0)

Availability of healthy drinking water and providing electrolytes (D): Yes (1), No (0)

Having a second job (E): Yes (1), No (0)

Personal protective plans (F): Yes (1), No (0) 
Table 2. Extractedcriteria by Using Experts' Viewpoints

\begin{tabular}{|c|c|}
\hline \multicolumn{2}{|l|}{ Extracted Criteria } \\
\hline Income (Subsistence Condition) & 11 \\
\hline Training programs & 12 \\
\hline Job satisfaction & 13 \\
\hline Providing shaded areas & 14 \\
\hline Social security insurance & 15 \\
\hline Membership in trade unions & 16 \\
\hline Facilities for taking a shower after work & 17 \\
\hline Having a second job & 18 \\
\hline Regular exercise program & 19 \\
\hline Providing safety and health guidelines & 20 \\
\hline Administrative Controls & 1 \\
\hline Engineering controls & 2 \\
\hline Accessing to healthy drinking water & 3 \\
\hline Providing the body electrolytes & 4 \\
\hline special places for rest & 5 \\
\hline Personal protective plans & 6 \\
\hline Suitable working clothes & 7 \\
\hline Local cooling systems & 8 \\
\hline Proper diet & 9 \\
\hline Existence of HSE unit & 10 \\
\hline
\end{tabular}

Table 3. Final Extracted Criteria for Adaptability Parameter

\begin{tabular}{|llc}
\hline No & Extracted Criteria & No. (\%) \\
\hline $\mathbf{1}$ & Administrative controls & $30(100)$ \\
\hline $\mathbf{2}$ & Engineering controls & $26(86.6)$ \\
\hline $\mathbf{3}$ & Providing special places for rest and shaded area & $21(70)$ \\
\hline $\mathbf{4}$ & $\begin{array}{l}\text { Accessing to healthy drinking water and providing } \\
\text { electrolytes }\end{array}$ & $18(60)$ \\
\hline $\mathbf{5}$ & Having a second job & $16(53.3)$ \\
\hline $\mathbf{6}$ & Personal protective plans & $14(46.6)$ \\
\hline $\mathbf{7}$ & Suitable working clothes & $14(46.6)$ \\
\hline $\mathbf{8}$ & Existence of HSE unit & $14(46.6)$ \\
\hline $\mathbf{9}$ & Training programs & $11(36.6)$ \\
\hline $\mathbf{1 0}$ & Job satisfaction & $10(33.3)$ \\
\hline $\mathbf{1 1}$ & Social security insurance & $9(30)$ \\
\hline $\mathbf{1 2}$ & Membership in trade unions & $8(26.6)$ \\
\hline $\mathbf{1 3}$ & Regular exercise program & $7(23.3)$ \\
\hline & &
\end{tabular}

Suitable working clothes (G): Yes (1), No (0)

Existence of HSE unit (H): Yes (1), No (0)
Training programs (I): Yes (1), No (0)

Job satisfaction (J): Yes (1), No (0)

Social security insurance (K): Yes (1), No (0)

Membership in trade unions (L): Yes (1), No (0)

Regular exercise program (M): Yes (1), No (0)

According to the equation (7), the adaptability level is defined between 0 to 1 .

\section{Discussion}

Heat-related illnesses and death are widely preventable. Heat stress management and control can increase productivity and comfort and reduce the cost related to health problems. Work-related injuries occurred due to the concurrent hazards in the workplace, so rarely an injury has a single cause. Taking effective preventive measures for workers' adaptation to heat may lead to reduction in heat stress. However, controlling heat stress in outdoors is more difficult than that of indoors. Immediate and short-term control measures are considered against the heat for minimizing effects of heat stress. In addition, some measures for workers' adaptation to heat are taken into account as long-term procedures $(14,24)$.

In this study, 13 criteria were extracted based on the percentage of experts' responses (Table 3). Then, FAHP was used for pair-wise comparisons of 13 criteria considering their importance. According to Table 3, the maximum percentages of responses were allocated to administrative and engineering controls. As presented in Table 4, the highest relative weight (0.156) was obtained for engineering controls, indicating the importance of this criterion in hot environments with respect to experts' viewpoints. The most important method of controlling the heat in the workplace is engineering controls including the increase of air flow (fan), general ventilation and air conditioning, and reduction of radiation heat using proper shields. Despite the fact that there is no exposure to direct solar radiation, indoor workers may be exposed to heat and humidity resulted from work processes. When there is no cooling system or sufficient ventilation, such indoor workplaces can become very hot during hot days $(25,26)$.

Epidemiological studies have indicated that air conditioning leads to decreasing risk of heat-related illnesses up to $80 \%$. Also, $30 \%$ reduction of the mentioned risk is expected with applying a fan in hot workplaces (27).

A ventilation system is necessary to reduce the temperature of work environment according to the following methods:

Heat sources such as heat generation machines should be isolated in the workplace. If it is not possible to keep workers away from heat sources, insulators can be used to minimize the thermal radiation. 
Table 4. The Evaluation Matrix Coefficients and Membership Functions for Criteria

\begin{tabular}{|c|c|c|c|c|c|}
\hline No & Extracted Criteria & Relative Fuzzy Weight & $\mathbf{u}$ & $\mathbf{m}$ & $\mathbf{I}$ \\
\hline 1 & Administrative controls & 0.099 & 0.11 & 0.097 & 0.090 \\
\hline 2 & Engineering controls & 0.156 & 0.162 & 0.156 & 0.150 \\
\hline 3 & Personal protective plans & 0.073 & 0.085 & 0.071 & 0.063 \\
\hline 4 & Accessing to healthy drinking water and providing electrolytes & 0.109 & 0.116 & 0.109 & 0.102 \\
\hline 6 & Suitable working clothes & 0.090 & 0.098 & 0.093 & 0.079 \\
\hline 7 & Having a second job & 0.028 & 0.034 & 0.028 & 0.023 \\
\hline 8 & Existence of HSE unit & 0.081 & 0.087 & 0.082 & 0.074 \\
\hline 9 & Training programs & 0.08 & 0.093 & 0.078 & 0.069 \\
\hline 10 & Job satisfaction & 0.056 & 0.066 & 0.054 & 0.048 \\
\hline 11 & Social security insurance & 0.035 & 0.043 & 0.035 & 0.027 \\
\hline 12 & Membership in trade unions & 0.024 & 0.031 & 0.023 & 0.018 \\
\hline 13 & Regular exercise program & 0.053 & 0.063 & 0.055 & 0.041 \\
\hline
\end{tabular}

Proper ventilation system such as fans and blowers should be used to increase the airflow in the workplace.

In case of poor ventilation, using appropriate methods is recommended to move the hot air out of the indoor environment $(28,29)$.

About $70 \%$ of the experts selected the criterion of providing shaded area and special resting places, and the relative weight allocated to this criterion was 0.116. The use of temporary covers such as umbrellas or sun shades at workplace is recommended to prevent direct exposure to sunlight or heat radiation source. The type of sun shade and its direction should be specified in health and safety programs. The sunshade should be well-ventilated and include chairs and appropriate drinking water. The portable sunshades can be used in outdoor environments $(26,30)$.

Other criterion in this study was accessing healthy drinking water and providing electrolytes with response percentage of $60 \%$ and the relative weight of 0.109 . Suitable and adequate facilities for cool water close to the workers should be considered in the workplace. Healthy and cool water should be provided for all workers in large workplaces such as construction sites. Caffeinated drinks such as tea and coffee should be avoided to prevent sleep related problems during the work shift. Body may lose too much fluid via sweating due to working in hot environments. Not replacing the lost water leads to serious heatrelated consequences $(31,32)$.

A survey in 2005 showed that $72 \%$ of people with heatrelated problems did not drink water despite having access to it (33). Another study (2007) was conducted on workers of surface mines located in Pilbara in Western Australia; and the results obtained from urine samples revealed that $70 \%$ of 710 workers were subjected to water scarcity and that $16 \%$ of workers needed clinical services (34). Similar conditions were reported for construction workers in Iran (35) and United Arab Emirates (34). Education is important in helping workers maintain their hydration state. Some organizations such as NIOSH recommend drinking small amounts of water several times (a maximum of 1 cup (250 $\mathrm{mL}$ ) every 15 to 20 minutes) (36).

Another criterion for adaptability is administrative control plans with $100 \%$ response and relative weight of 0.099. Administrative control is a useful procedure to reduce heat-related illnesses and deaths in the workplace. Duration of work can be adjusted to reduce exposure to heat. Heavy work activities in outdoors and maintenance operations may be scheduled for cooler hours of the day or cooler seasons of the year. Physical work demands should be reduced as much as possible with mechanizing the work. Providing an appropriate work-rest cycle and limited work schedules with rest periods and working in cooler places are considered to reduce the exposure to heat $(37,38)$.

Acclimatization is an important administrative control step in hot environments (39). This is a low-cost physiological procedure used to ensure the health and safety of workers and to mitigate the heat strain. For workers who are not acclimatized to working in hot conditions, enough time should be provided for adaptation to heat. For example, lowering the pace and the intensity of work and considering a work-rest schedule for unacclimatized workers are recommended. In addition, heat tolerance tests are 
used to screen workers who are susceptible to heat. It is suggested to attend to potential risk factors such as taking certain medications and special medical conditions, which may adversely affect thermoregulatory center in the body. Excessive alcohol consumption, lack of physical fitness, improper body mass index, and high blood pressure can affect the prevention of heat strain (40).

The next criterion extracted by experts was suitable working clothes. The response percentage of $46.6 \%$ and the relative weight of 0.090 was obtained for it. Clothing affects the heat transfer mechanisms between human and environment via convection, radiation, and evaporation. Therefore, using appropriate clothing in hot environments leads to reducing heat-related disorders and increasing the worker efficiency. Clothing, as an insulator, affects heat transfer processes. Thin, light-colored, and relatively loose-fitting clothing can help the heat loss in hot environments (41). A practical method to control heat strain in hot environments is cooling clothes (cooling vests), produced in late 1950s. Using air permeable clothes increases their ventilation rates. Air-conditioned clothes or clothes with light-weight fans can be used in hot environments. Passive cooling systems use phase-change materials (PCMs) in the vests and clothes to provide extra cooling. The PCMs are substances with latent heat storage that absorb or release heat during phase change (for example, changing from solid to liquid). Providing greater mobility and saving energy are the advantages of personal cooling clothes with PCMs compared to stationary personalized or building cooling (17).

The response percentage of $36.6 \%$ and relative weight of 0.08 were allocated to the criterion of training programs related to the risk of heat stress. Proper training for workers and managers should be provided before the start of the hot months of the year. Training should include the following elements:

Understanding the risks of working in hot environments

The effects of heat stress and related safety measures

Identifying risk factors, signs, and symptoms of heat stroke

Assessing the heat stress

Training how to use proper devices to monitor the hot weather and the heat stress

Relevant legal requirements

First aid and emergency procedures in case of the heat stroke

Appropriate first aid equipment should be provided in the work environment. When heat-related injuries occur, the person should immediately be taken out of the heat to rest in a cool and air-conditioned place. If symptoms continue, the person should be transferred to the hospital (26,
$32,42)$.

Accessing personal protective equipment (PPEs) was another selected criterion with response percentage of $46.6 \%$ and relative weight of 0.073 . Personal protective equipment is a highly effective and economical means to reduce the heat stress, adapt to hot conditions, and increase the duration of work in hot environments, which is essential for outdoor workers. These workers are encouraged to use naturally-ventilated helmet to enhance perspiration. Also, to provide shade to the face, neck, and back, the use of safety helmets with broad brim is recommended. Vests with cooling flows improve the working conditions. In 2013, the labor administration and occupational health and safety administration (OSHA) implemented a pilot scheme for using cooling vests to reduce the risk of heat stroke during the summer. The type, size, and color of clothing can affect the heat transfer between the human body and the environment (29).

Having a second job can be an effective criterion for adaptability; its response percentage was $53.3 \%$ with a relative weight of .028. The second job causes the decrease of worker's physical fitness, resulting in the reduction of the adaptability. In the other word, adaptation to heat for anyone requires a minimum of repeated exposure to heat, and the second job interferes with this requirement. A study conducted by Tirgar et al. showed that more than $40 \%$ of farmers had a second job. However, considering the conditions of the agricultural industry, this result was not unique to this study and is expected in other countries (42).

In 2013, Vietnam's development and health committee evaluated the adaptation capacity of outdoor workers (construction workers, farmers, and porters) to extreme heat. In this study, countermeasures against heat included instant and short-term responses, and the adaptation measures consisted of long-term ones. Administrative controls including the following criteria were considered in mentioned measures.

Providing suitable protective clothing

Providing appropriate PPEs such as masks, gloves, creams, and glasses

Providing sufficient water

Appropriate short breaks

Taking a long lunch break and avoid working in the midday heat

Changing the working hours

Most of respondents reported that enough water as well as protective clothing or personal protective equipment had been provided for them by employers. Less than half of respondents reported that they could not have a short break during shifts or during lunch time to protect themselves from the heat. Regular short breaks in shaded areas are commonly advised to outdoor workers 
who work in extreme heat. Furthermore, it is suggested that cool drinking water, personal protective equipment (sunglasses, hats, and masks), and bright color clothes be provided to workers (43).

Miller et al. (2007) studied workers exposed to the extreme heat stress. Finally, they offered some recommendations for outdoor workers such as consuming enough water, providing cooling water and electrolytes close to the workers, and not nonuse of the caffeinated drinks before and during the work shift (33).

Several studies expressed some adaptive responses to heat stress including acclimatization in a hot environment, providing shade, health education, and increase in use of air conditioners, modifying behavior patterns, emergency response programs, and warning systems. In addition, some protective guidelines have been published in developed and developing countries to protect workers exposed to heat $(43,44)$.

Managing heat stress in the workplace requires the cooperation of all members and it is not the responsibility of workers. Heat stress and heat-related problems in the workplace have not been considered as a priority for decision- makers. In addition, there are no effective policies and heat stress awareness guidelines related to heat exposure in developing countries.

\subsection{Conclusions}

Exposure to extreme heat in the workplace can cause various types of heat related-illnesses. The combination of various control methods are required to protect the workers from heat stress. Considering some measures for worker adaptation to heat may lead to reduction in the heat stress. Adaptation results in reducing the vulnerability and increasing the heat tolerance. There are some important criteria for adaptability to heat in the workplace. Using these criteria, the present study has proposed a model for estimation of the workers' adaptability to heat stress. After extraction of the most important criteria by Delphi model and determining their weights by FAHP, a model was introduced to estimate the adaptability to heat. Administrative controls, engineering controls, and providing shaded area and special places for rest were considered as effective criteria for adaptability. In conclusion, employers should develop a heat stress policy to reduce the potential for heat-related illnesses. Considering some points is recommended in this policy. In fact, a combination of following ways is suggested for adaptation to heat: training to recognize symptoms of the heat stress; providing enough water close to the workplace; providing lightcolored loose fitting clothing for workers; providing wellventilated and shaded places for rest break; and planning a scheduled work programs to minimize heat exposure. The development and implementation of the mentioned policy require the cooperation of all members including employers, health and safety committee, supervisors, and employees.

\section{Acknowledgments}

This research has been sponsored by institute for environmental research (Grant No.94-01-46-28540). We are thankful to our colleagues, the professors of occupational health departments, postgraduate students, and the personnel of environmental and occupational health center in the ministry of health, who provided expertise that greatly assisted the research. The authors declare that there is no conflict of interest.

\section{References}

1. Asghari M, Nassiri P, Monazzam MR, Golbabaei F, Arabalibeik $H$, Shamsipour A, et al. Weighting Criteria and Prioritizing of Heat stress indices in surface mining using a Delphi Technique and Fuzzy AHPTOPSIS Method. J Environ Health Sci Eng. 2017;15(1). doi: 10.1186/s40201016-0264-9. [PubMed: 28101366].

2. Nassiri P, Monazzam MR, Golbabaei F, Dehghan SF, Rafieepour A Mortezapour AR, et al. Application of Universal Thermal Climate Index (UTCI) for assessment of occupational heat stress in open-pit mines. Ind Health. 2017;55(5):437-43. doi: 10.2486/indhealth.2017-0018. [PubMed: 28804096].

3. Vangelova K, Deyanov C, Ivanova M. Dyslipidemia in industrial workers in hot environments. Cent Eur J Public Health. 2006;14(1):15-7. [PubMed: 16705875].

4. Schulte PA, Chun H. Climate change and occupational safety and health: establishing a preliminary framework. J Occup Environ Hyg. 2009;6(9):542-54. doi: 10.1080/15459620903066008. [PubMed: 19551548].

5. Kjellstrom T, Gabrysch S, Lemke B, Dear K. The 'Hothaps' programme for assessing climate change impacts on occupational health and productivity: an invitation to carry out field studies. Glob Health Action. 2009;2. doi: 10.3402/gha.v2i0.2082. [PubMed: 20052425].

6. Intergovernmental Panel on Climate Change (IPCC) . Fourth Assessment Report, Geneva. Cambridge: Cambridge University Press; 2007.

7. Nilsson M, Kjellstrom T. Climate change impacts on working people: how to develop prevention policies. Glob Health Action. 2010;3. doi: 10.3402/gha.v3i0.5774. [PubMed: 21140000].

8. NIOSH . Niosh criteria for a recommended standard: Occupational exposure to heat and hot environments. National Institute for Occupational Safety and Health; 1986.

9. U.S. Department of Health and Human Services . Morbidity and mor tality weekly report, heat-related deaths among crop workers, 1992-2006. United States; 2008. Report No.: 1017-1018.

10. Inaba R, Mirbod SM. Comparison of subjective symptoms and hot prevention measures in summer between traffic control workers and construction workers in Japan. Ind Health. 2007;45(1):91-9. [PubMed: 17284880].

11. US Department of Health and Human Services. Working in hot environments. Cincinnati, OH: NIOSH, Centers for Disease Control and Prevention (CDC); 2006.

12. Bureau of Labor Statistics UOL. Fatal occupational injuries by event or ex posure and major private industry. Washington, D.C: The National Census of Fatal Occupational Injury; 2009. 
13. Health CDoOSa. Heat - related illness prevention. California: Division of Occupational Safety and Health; 2007.

14. Wolf J, Lorenzoni I, Few R, Abrahamson V, Raine R. Conceptual and practical barriers to adaptation: Vulnerability and responses to heat waves in the UK. In: Adger N, Lorenzoni I, O'Brien K, editors. Adapting to climate change: Thresholds, values, governance. Cambridge: Cambridge University Press; 2011. p. 181-96.

15. Paavola J. Livelihoods, vulnerability and adaptation to climate change in Morogoro, Tanzania. Environ. Sci. Policy. 2008;11(7):642-54.

16. Intergovernmental Panel on Climate Change (IPCC). Third Assessment Report. United Nations Framework Convention on Climate Change, Marrakech; 2001. 982 p.

17. Lundgren K, Kuklane K, Gao C, Holmer I. Effects of heat stress on working populations when facing climate change. Ind Health. 2013;51(1):315. [PubMed: 23411752]

18. Vidal LA, Marle F, Bocquet JC. Using a Delphi process and the Analytic Hierarchy Process (AHP) to evaluate the complexity of projects. Expert Syst Appl. 2011;38(5):5388-405.

19. Okoli C, Pawlowski SD. The Delphi method as a research tool: An example, design considerations and applications. Inf Manage. 2004;42(1):15-29.

20. Ayag Z, Ozdemir RG. A fuzzy AHP approach to evaluating machine tool alternatives. J Intell Manuf. 2006;17(2):179-90.

21. Gumus AT. Evaluation of hazardous waste transportation firms by using a two step fuzzy-AHP and TOPSIS methodology. Expert Syst Appl. 2009;36(2):4067-74.

22. Hsieh TY, Lu ST, Tzeng GH. Fuzzy MCDM approach for planning and design tenders selection in public office buildings. Int J Proj Manage. 2004;22(7):573-84.

23. Alavi I. Fuzzy AHP method for plant species selection in mine reclamation plans: Case study Sungun copper mine. Iran J Fuzzy Syst. 2014;11(5):23-38.

24. Sung TI, Wu PC, Lung SC, Lin CY, Chen MJ, Su HJ. Relationship between heat index and mortality of 6 major cities in Taiwan. Sci Total Environ. 2013;442:275-81. doi: 10.1016/j.scitotenv.2012.09.068. [PubMed 23178831].

25. Xiang J, Bi P, Pisaniello D, Hansen A. Health impacts of workplace heat exposure: an epidemiological review. Ind Health. 2014;52(2):91101. [PubMed: 24366537].

26. Morioka I, Miyai N, Miyashita K. Hot environment and health problems of outdoor workers at a construction site. Ind Health. 2006;44(3):474-80. [PubMed: 16922192].

27. Naughton MP, Henderson A, Mirabelli MC, Kaiser R, Wilhelm JL Kieszak SM, et al. Heat-related mortality during a 1999 heat wave in Chicago. Am J Prev Med. 2002;22(4):221-7. [PubMed: 11988377].

28. OSHA.NIOSH. Protecting workers from heat illness. Occupational Safety and Health Administration; 2011.
29. CIC . Guidelines on site safety measures for working in hot weather. Construction Industry Council (CIC); 2013.

30. Ministry of Health Law. Prevention of Heat Stress in the Workplace (In J). Ministry of Health Law; 2012.

31. Jung AP, Dale RB, Bishop PA. Ambient-temperature beverages are consumed at a rate similar to chilled water in heat-exposed workers. J Occup Environ Hyg. 2007;4(1):54-7. doi: 10.1080/15459620601074916. [PubMed: 17162481].

32. Jackson LL, Rosenberg HR. Preventing heat-related illness among agricultural workers. J Agromedicine. 2010;15(3):200-15. doi: 10.1080/1059924X.2010.487021. [PubMed: 20665306].

33. DIR. Heat illness prevention etool. 2012. Available from: http://www.dir. ca.gov/dosh/etools/08-006/EWP_training.htm..

34. Bates GP, Schneider J. Hydration status and physiological workload of UAE construction workers: A prospective longitudinal observational study. J Occup Med Toxicol. 2008;3:21. doi: 10.1186/1745-6673-3-21. [PubMed: 18799015].

35. Montazer S, Farshad AA, Monazzam MR, Eyvazlou M, Yaraghi AA, Mirkazemi R. Assessment of construction workers' hydration status using urine specific gravity. Int $J$ Occup Med Environ Health. 2013;26(5):762-9. doi: 10.2478/s13382-013-0143-x. [PubMed: 24464540].

36.

37. Bray P, Sokas R, Ahluwalia J. Heat-related illnesses: opportunities for prevention. J Occup Environ Med. 2010;52(8):844-5. doi: 10.1097/JOM.ob013e3181ed4c36. [PubMed: 20697228].

38. Centers for Disease C.Prevention. Heat-related deaths among crop workers-United States, 1992-2006. MMWR Morb Mortal Wkly Rep. 2008;57(24):649-53. [PubMed: 18566563].

39. Di Corleto R, Firth I, Coles G. Heat stress standard documentation developed for use in the Australian environment. Austra Inst Occup Hyg. 2003.

40. Jay O, Kenny GP. Heat exposure in the Canadian workplace. Am J Ind Med.2010;53(8):842-53. doi:10.1002/ajim.20827. [PubMed: 20623643].

41. Parvari RA, Aghaei HA, Dehghan H, Khademi A, Maracy MR, Dehghan SF. The Effect of Fabric Type of Common Iranian Working Clothes on the Induced Cardiac and Physiological Strain Under Heat Stress. Arch Environ Occup Health. 2015;70(5):272-8. doi: 10.1080/19338244.2014.891965. [PubMed: 24971773].

42. Tirgar ASA, Haji Ahmadi M, Hosseini R. Determination of susceptibility to heat-related disorders and prevention methods among agriculture workers. Jarvis Hall Tech Wing. 2012;1(1):39-46.

43. Kovats RS, Jendritzky G. Heat-waves and human health. In: Menne $\mathrm{B}$, Ebi KL, editors. Climate change and Adaptation Strategies for Human Health. Darmstadt: WHO; 2006. p. 63-97.

44. Bates GP, Miller VS, Joubert DM. Hydration status of expatriate manual workers during summer in the middle East. Ann Occup Hyg. 2010;54(2):137-43. doi: 10.1093/annhyg/mep076. [PubMed: 19959561]. 